\title{
Six Categories of Illnesses
}

\author{
Paul Valent \\ Liaison Psychiatrist (retd.) Monash Medical Centre, Melbourne, Australia \\ Email: p.valent@bigpond.net.au
}

Received April 15 ${ }^{\text {th }}$, 2013; revised May $17^{\text {th }}$, 2013; accepted June $16^{\text {th }}, 2013$

\begin{abstract}
Copyright (C) 2013 Paul Valent. This is an open access article distributed under the Creative Commons Attribution License, which permits unrestricted use, distribution, and reproduction in any medium, provided the original work is properly cited.
\end{abstract}

\begin{abstract}
Studies show that between $40 \%$ and $60 \%$ of patients attending emergency departments have medically unexplained physical symptoms (MUPS) that are determined by psychosocial factors. However, there exists no clear categorization of these factors and the symptoms that they produce. This paper delineates six categories of illnesses that help to overcome this deficit. The categories of illnesses are 1) Typical physical illnesses; 2) Typical psychiatric illnesses; 3) Psychophysiological symptoms; 4) Symptoms associated with reliving traumas; 5) "Cherished" or hysterical symptoms; 6) Symptoms that identify with illnesses of others. Clinical examples of each category are provided.
\end{abstract}

Keywords: Medically Unexplained Physical Symptoms; MUPS; Psychophysiological; Psychosomatic; Somatization; Hysteria

\section{Introduction}

An example of the conflict between philosophy and fact can be seen in treatment of patients in emergency departments. The philosophy goes back to the Cartesian dichotomy of mind and body. Doctors see themselves as treating the body. The rest is not their concern. The fact is that doctors' patients are an amalgam of body, mind, and society and the sources of their physical symptoms are frequently a result of psychosocial factors.

The result of the dichotomy between fact and philosophy is that between $40 \%$ and $60 \%$ of patients attending emergency departments finish with medically unexplained physical symptoms (MUPS) (Stephenson \& Price, 2006).

Apart from the misery this causes patients, the situation is very costly (Abbas, Campbell, Han et al., 2010). Instead of their problems being dealt with, patients are sent on merry-gorounds of ever-more expensive tests and referrals in efforts to fit their symptoms into Procrustean beds of medical illnesses.

Doctors are reluctant to seek out psychosocial factors underlying physical symptoms. They feel untrained to deal with the Pandora's box of emotion and chaos they believe they may unleash. But there is also no theoretical framework that can help them to apportion symptoms to heuristically treatable categories.

Vague warnings that stress can cause illness, and diagnoses such as hypochondriasis, dissociation, factitious disorder and malingering (Stephenson \& Price, 2006) do not help to distinguish symptoms from "genuine" physical disorders.

The following approach is the result of our team's experience in the emergency department at Monash Medical Centre over more than 20 years. Earlier versions of this approach have been described elsewhere (Valent, 1979, 1998).

The approach recognises six categories of illness. Each is recognisable and leads to pragmatic interventions.

\section{Six Categories of Illness}

\section{Typical Somatic Illnesses}

These illnesses provide the least difficulty as they are textbook medical cases. Examples are acute appendicitis, urinary tract infection, and myocardial infarct.

And yet even here it is worth looking at psychosocial factors.

Case 1: A child had her first attack of asthma during a parental quarrel where the father threatened to leave home. Subsequent attacks recurred during similar quarrels. In adulthood the patient was prone to asthma attacks when threatened with separation from loved ones. The attacks incidentally inclined people not to leave her.

Case 2: A young woman presented with polyneuritis (Guillain-Barre syndrome). This developed within days of a fire that destroyed the family home and business. She believed that it was her fault and that she nearly caused the death of her sister. She believed that she had forfeited any love for the rest of her life. (For a full description of this case see Valent (2009).

\section{Illnesses with a Psychiatric "Signature"}

Some physical symptoms are part and parcel of major psychiatric illnesses. Sleep disturbance, anorexia, constipation, tiredness, exhaustion are classical accompaniments of major depression. Bizarre symptoms such as ants crawling under the skin, sense that one's scalp is lifting, foreign agents regulating physiological functions all have a schizophrenic signature.

Case 3: A woman presented with extreme tiredness after the death of her husband. She also lost all interest and looked depressed. When she grieved her husband her tiredness lifted along with her depression.

Case 4: A schizophrenic man suffered a constant level of nausea that he attributed to the neighbours poisoning him with asbestos. 


\section{Psychophysiological Symptoms}

Because the sympathetic and parasympathetic nervous systems and stress hormones reach and influence every organ of the body, their arousal in stress can result in a very wide range of symptoms that include potential arousal and dampening of every bodily system. Musculo-skeletal tension symptoms include headache, neck ache, chest pain, and back ache. Digestive system symptoms include loss of appetite, weight loss, weight gain, nausea, constipation, diarrhoea, etc. Cardiovascular symptoms include palpitations, shortness of breath, chest pains, high blood pressure. Urino-genital system symptoms include bladder pressure, frequency, dysmenorrhea, painful intercourse.

Psychophysiological symptoms can mimic at least in part most physical disorders.

Case 5: A woman who attended her GP with recurrent head, neck, and back pains was found to suffer from tension that resulted from bracing against her husband's violent outbursts.

Case 6: The first time a patient developed migraine was when she witnessed Nazis vandalise her grandmother's shop in Vienna on Krystallnacht. She felt a fury toward those who made her grandmother collapse in the street. However she was impotent to vent her rage. Throughout her life migraines recurred at times when she had to bottle up her anger.

\section{Reliving Traumatic Situations}

Dissociated aspects of traumatic situations may be relived as physical symptoms.

Case 7: A combat veteran kept returning to hospital with chest pain which he was convinced was sign of a heart attack. The pain did not conform to heart disease and all tests were normal. On closer questioning the pain was a wrenching of the heart, as if it incurred a wound, or as if it was broken. It was the exact pain he felt when his buddy died in his arms. Grieving relieved the physical pain.

Case 8: A woman experienced severe physical pain each time her husband penetrated her. The pain was a replica of the pain she suffered when an uncle penetrated her as a child.

\section{Identification with Illnesses of Others}

Patients often identify with symptoms and illnesses of those they love, especially of those who had died. This is a result of empathy, guilt, and not having let go. Symptoms often arise during the loved person's terminal illness, after bereavement, at anniversaries, and when attaining the age of the loved person (such as a parent of the same sex).

The symptoms are often unusual because they reflect patients' concepts of what others suffered, and such concepts may be anatomically untenable.

Case 9: A month after her husband's death of a heart attack, a woman presented with a sharp stabbing pain over her left nipple. She believed that she was having a heart attack like her husband.

Case 10: A 12-year-old girl was brought to hospital after she carelessly rode in front of an oncoming car. Two years earlier her sister, then 12 was killed on her bike in a collision with a car. The younger sister blamed herself for her sister's death and had fantasies of joining her in heaven.

\section{“Cherished" Illnesses; Hysteria}

It goes against the medical grain to consider that suffering may be cherished. Patients who cherish their symptoms arouse frustration because they do not comply with treatment, their symptoms migrate, and they adopt fashionable diagnoses that are difficult to diagnose and treat.

Once suspicion is aroused, diagnoses only thinly veil anger. Diagnoses include "secondary (financial) gain”, "hysteric", factitious disorder, Munchausen's syndrome, and malingering.

In reality, apart from the few cases of malingering, cherished illnesses obey classical rules of hysteria. The symptoms are produced through unconscious processes; they symbolise a major stress or trauma; whose consequences the symptoms help to resolve this being primary gain; and they are secondarily used for other gains (secondary gains). The classical example was the World War One soldier whose paralysis of the right arm necessitated his withdrawal from combat.

Case 11: A previously somewhat pampered inductee was bullied by his army colleagues who teased him as not having "guts" or "stomach" for the army. After a mild punch to his stomach he developed severe abdominal cramps that did not respond to treatment. Eventually he was "honourably" discharged.

Case 12: A previously hard working man developed back pain after lifting a heavy object. His disability was beyond any objective pathology. The man's wife withdrew from sex after her doctor advised her that she would die if she had another child. The man, however, suspected that his wife had a lover while he was at work. Staying at home enabled him to keep a watchful eye over her. Secondarily, his disability evoked concern from his wife, as well as worker's compensation.

\section{Discussion}

The six categories of illnesses present a heuristically useful way of conceptualising illnesses. Rather than consigning symptoms that do not meet typical somatic criteria to a waste-basket of therapeutic nihilism, a checklist of illness categories may find that the symptoms fit precisely into one of the non-somatic categories.

Considering the frequency of MUPS, this has clinical implications for approaches to all patients. Such approaches have been called holistic, and biopsychosocial. I prefer to call for a wholist approach (Valent, 1998a) that includes both biopsychosocial and whole. In addition to biological, psychological, and social interactions, the approach concerns itself also with moral dilemmas and existential meanings. They were very relevant in the above cases.

Pragmatically, a somatic approach like "Tell me about the pain", is replaced with an open-minded question such as "Of all the things that worry you what worries you the most?".

All histories should include questions such as "Have you been under stress or experienced trauma recently/when the symptoms started?”, “Apart from these symptoms do you have any others/any other worries/frustrations/conflicts?”, "Have you been depressed/anxious/experienced other strange symptoms?", "Have you known anyone else who suffered these symptoms?", "If you could have any desire fulfilled, what would it be?".

When patients reveal the emotions and contexts of their worries, it is not so much that a Pandora's box opens with evermore problems, but rather that a box under pressure opens akin to the release of an abscess.

The categories enable making positive psychosocial diagnoses. Further, diagnoses are confirmed when symptoms recur 
when stresses return or when they are reproduced in fantasy. They resolve when the stresses are resolved.

An interesting test is over breathing for half a minute. This often reproduces psychophysiological and other psychosocial symptoms. Re-breathing in a paper bag diminishes them.

Of course categories, diagnoses, and treatments are not always simple. Categories themselves may be difficult to ascertain, and they can be multiple and overlap. Further, presence of a non-somatic category does not mean that a somatic one does not exist as well.

\section{Conclusion}

Six categories of illnesses provide a step toward a heuristic conceptualisation of what are otherwise medically unexplained physical symptoms.

An advantage of the non-somatic categories is that they connect with the initial disruptive conditions, their consequences, and the existential meanings the symptoms symbolise. Treatment can repair the disruptions, resolve the symptoms, and provide new meanings.

Though symptoms may not always be easily classified, diagnosed, and treated, the expanded categories do provide extended tools for diagnosing physical symptoms without classi- cal medical explanations.

\section{REFERENCES}

Abbass, A., Campbell, S., Hann, S. G., Lenzer, I., Tarzwell, R., \& Maxwell, R. (2010). Cost savings of treatment of medically unexplained symptoms using Intensive Short-Term Dynamic Psychotherapy (ISTDP) by a hospital emergency department. Archives of Medical Psychology, 7, 34-43.

Stephenson, D. T., \& Price, J. R. (2006). Medically unexplained physical symptoms in emergency medicine. Emergency Medicine Journal, 23, 595-600. doi:10.1136/emj.2005.032854

Valent, P. (1979). Psychosomatic aspects of illness. Patient Management, 8, 21-28.

Valent, P. (1998). Trauma and fulfilment therapy; A wholist framework. Philadelphia, PA: Brunner/Mazel.

www.paulvalent.com/books/trauma-and-fulfillment-therapy/\#more-7 96

Valent, P. (1998a). From survival to fulfilment; A framework for the life-trauma dialectic. Philadelphia, PA: Brunner/Mazel.

www.paulvalent.com/books/from-survival-to-fulfillment/\#more-793

Valent, P. (2009). In two minds; Tales of a psychotherapist. Sydney: University of New South Wales Press.

www.paulvalent.com/books/in-two-minds-tales-of-a-psychotherapist /\#more-205 